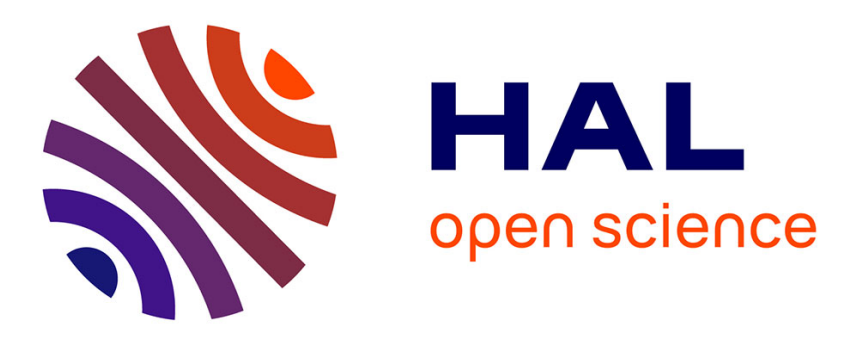

\title{
Governing radical change through the emergence of a governance arrangement
}

Aurélie Delemarle, Philippe Larédo

\section{To cite this version:}

Aurélie Delemarle, Philippe Larédo. Governing radical change through the emergence of a governance arrangement. The Governance of Socio-Technical Systems - Explaining Change, 2014, Eu-SPRI Forum on Science, Technology and Innovation Policy series 978178471018 7. hal-01273361

\section{HAL Id: hal-01273361 \\ https://hal.science/hal-01273361}

Submitted on 12 Feb 2016

HAL is a multi-disciplinary open access archive for the deposit and dissemination of scientific research documents, whether they are published or not. The documents may come from teaching and research institutions in France or abroad, or from public or private research centers.
L'archive ouverte pluridisciplinaire HAL, est destinée au dépôt et à la diffusion de documents scientifiques de niveau recherche, publiés ou non, émanant des établissements d'enseignement et de recherche français ou étrangers, des laboratoires publics ou privés. 
Governing radical change through the emergence of a governance arrangement.

\title{
Aurelie Delemarle and Philippe Larédo
}

\author{
A revised version is being published in Borras and Edler (2014), The governance \\ of socio-technical systems, Edward Elgar.
}

\section{Introduction}

This chapter investigates the process through which radical change is governed focusing on the activities of actors from a market perspective, from public policy makers to industrialists and to consumers. Considering the idea that markets can be organised and shaped, we follow the activities of those that Courtney et al. (1997) call "market shapers". The literature related to such topic has been scattered. On the one hand, a stream of the literature deals especially with the role of a few individuals and their social and political skills to allow change (Fligstein, 1996; Fligtsein and Mara Drita, 1996 on political entrepreneurs; Lawrence and Suddaby, 2006 on institutional entrepreneurs). On the other hand, another stream of the literature has been focusing on the interactions between various levels (landscape, regime, niche) to explain radical change (such as the multi-level perspective (Geels, 2002, 2005) and strategic niche management). We argue that the two perspectives are complementary. This is made possible by focusing on the actors' activities rather than on the actors or their strategies only. It would thus enlighten the debate on the governance of change.

To do so, we propose to follow the building of market infrastructures (Delemarle and Larédo, 2012 and Delemarle and Larédo, forthcoming) through the arenas that produce them. Market infrastructures are defined as a set of rules (what actors are allowed to do), of norms (what they ought to do) and of values (what they want to do). While some are intangible (embodied in the way actors behave), most are embedded in physical equipment (communication networks or transport networks and their support systems) and in formalized processes that build on specialized certification and validation bodies or/and in legal obligations (with corresponding legislative and enforcement structures). Such a definition assumes that there is not one infrastructure to frame a market, but a set of them that build a set of infrastructures. We show that there is no one single arena that produces it. We argue that the three sets of questions - through the 3 pillars - raised by Borrás and Edler in the introductory chapter cannot be addressed in only one single arena. On the contrary, a series of complementary/competing arenas are developed, each being led by different actors with different interests and different targets (Bonneuil et al., 2008). We thus take a different position from Kuhlmann (2007) and Callon and Rip (1992) who would tend to argue for a single forum. Actors invest in arenas depending on the projects/views they want to defend, depending on what they think is important for the governance of markets. Arenas evolve over time: they have their own dynamics, which cannot be thought without considering trans-arena dynamics. Our argument is that the governance of change in S\&T emerges as the various arenas get aligned, into what we call a "governance arrangement". A governance arrangement is thus defined as the constellation of arenas and their dynamics (intra and inter arena dynamics) that are aligned in a robust manner. Until the governance arrangement is set, existing uncertainties (technical or social) do not allow actors to move forward in the 
development of innovations and markets are not structured because the market infrastructures have not been agreed upon.

The chapter is organised as follows: we first review the useful concepts from policy analysis (Kuhlmann, 2002) and social study of science (Bonneuil et al. 2008) that deal with settings in which strategic actors debate. We enrich these with some learnings from "hybrid forum" (Callon and Rip, 1992) and sociology of science (Vinck, 1999, 2010). We then go in details into our case that we structure using the framework proposed by Borrás and Edler in the opening chapter. We then discuss our findings on arenas linked to the set up of the governance arrangement and propose a first characterisation of arenas. Conclusions follow last.

\section{From arenas to hybrid forums: towards a framework to better understand governance of S\&T change}

The concept of arena offers useful readings of the setting in which "individual and collective actors interact to define the cognitive and normative dimensions of a problem" (Bonneuil et al., 2008: 205). Initially developed by Strauss (Clarke, 1991) and then further elaborated in policy analysis (Kuhlmann, 2007 and Kuhlmann et al., 1999) and sociology of social problems, arenas point to a meso-level of analysis: actors negotiate within structures to reach a consensus or said otherwise to reach an alignment.

Bonneuil et al. (2008) focusing on the role of these arenas in framing problems in a public debate context argue that one arena cannot alone encompass all problems and that several arenas co-exist, each focusing on one problem or on one framing of a problem. So they can compete one against another. In the case of GMOs, they counted nine arenas each having its "own symbolic referential, hurdles and resources i.e. its own grammar". Each brought a large variety of actors around one framing of a problem, in their case study, problems linked to GMOs: economic, scientific, expert, regulatory, legal, political, media, activist and participatory. In their study, they show how trans-arena dynamics evolve over time. They explain the resulting different positioning of the GMO controversy in France and in the US by the dynamics of interactions between the arenas. In their conclusion they however point to the limit of their framework: "linking automatically orders of justification to specific types of arenas" (Bonneuil et al. 2008: 226) is too simplistic. This framework is useful to explain the existence of various arenas and their relationships in the context of S\&T change. However, it does not help in understanding the dynamics within the arenas.

The notion of hybrid forum (Callon and Rip, 1992), initially developed to discuss democracy in relation to technical choices, brings complementary elements to the functioning of such arenas. The notion of hybrid forum relies on two terms that are equally important: forums as "they are open spaces where groups can come together to discuss technical options involving the collective," and hybrid as "the groups involved and the spokespersons claiming to represent them are heterogeneous, including experts, politicians, technicians and laypersons who consider themselves involved. They are also hybrid because the questions and problems taken up are addressed at different levels in a variety of domains, from ethics to economic" (Callon 
et al., 2009, p. 18). Hybrid forums are much more fluid ${ }^{1}$ and less stable than arenas. Callon and his colleagues argue that hybrid forums bring together experts from three different poles (scientific, legal, socio-economic). Experts are not part of a single arena but are what constitute arenas. They are "mediators" who face multiple constraints and who try to reach a compromise that is robust technically, socially viable and legally acceptable. This is where the idea of fluidity is illustrated because constraints can change over time; as a result, this can lead to various types of compromises over time. They are fluid also because they are networks of alliances across organisations that can be rearranged as new issues emerge over time or as new enrolment occur. The three poles are interconnected and actors can move across them. The interactions between the three produce "an expertise" and an alignment. What is interesting is that the latter cannot be known ex ante because it results from a negotiation. The concept of hybrid forum thus brings insight into the dynamics of each arena explaining why it can grow or come into decay. It also points to the fact that compromises need to be socially viable and legally accepted, i.e. robust (Rip et al., 1995), which is a very important point in the governance of change.

So multiple arenas co-exist, some expand, some decay, as they manage (or not) to enrol new actors and mobilise around their framing of the problem. But how does a stabilisation occur? The stabilisation, or "punctualising" (as proposed by D. Vinck, 1999, 2010), occurs when some results or products of one arena are used by others. Indeed, each result or product produces a before and an after. Each is an endpoint reflecting an agreement between the actors but also a materialisation that can travel. It thus "punctualises" the previous network of actors. It offers then new possibilities of action.

We propose to build on these approaches to better understand the set up of the governance of change in S\&T systems: how does a multiplicity of arenas emerge (are they as "simplistic" and "mono-dimensional" as Bonneuil et al. show?), how do they evolve (what are their internal dynamics as Callon and Rip demonstrate, and how do their internal logics impact their dynamics) and how do they articulate and stabilise their relationships (how does "punctualising" occur?). The main argument of the chapter is that these arenas, their internal dynamics and interrelationships are what constitute at a given point in time a governance arrangement.

We present the case study using Borrás and Edler's framework developed in the introductory chapter. The three pillars - purposeful actors, instruments, and legitimacy - link well with the approaches presented above: indeed, the concept of arena encompasses well the idea of a constellation of arenas with various actors and the focus on their interrelationships. The hybrid forum brings the idea of negotiation and compromise within a specific structure. Both approaches deal with actors, their interests and their heterogeneity. Callon and Rip's hybrid forum points more specifically to instruments as hybrid forums aim at creating a consensus based on constraints, some of which are legal/regulatory ones. Both approaches deal with legitimacy issues with different emphasis: Callon and Rip's hybrid forum aims at creating some legitimacy in the context of technical democracy; Bonneuil et al.'s arenas point more indirectly to legitimacy as each arena relies on its own grammar and mechanisms for legitimacy building.

\footnotetext{
${ }^{1}$ This is in line with Callon's framing and overflowing concept developed in 1999.
} 


\section{Governing nanotechnology based markets}

We consider the nanotechnology case to illustrate the governance arrangement, i.e. the constellation of arenas and their dynamics (intra and inter arena dynamics) that are aligned in a robust manner. We know from past stories that only successful alignments stay while unsuccessful trials disappear. This is why we prefer to test the setting up of a new governance arrangement in an on-going case. We can thus follow the various public and private investments and how they are accounted for in the different arenas.

We chose "nanotechnologies" to test the notion of governance arrangement because it is a lively case and as we argue elsewhere (Delemarle and Larédo, forthcoming), governance is still at a tentative stage. The case is rich in terms of the multiplicity of actors involved, the variety of spaces in which they act and the diversity of concerns they push forward.

Nanotechnologies are generally considered to represent a radical technological shift. Working at the nanoscale enables scientists to harvest new properties that do not exist at larger scales, so as either to add new functions to existing products (like waterrepellent glass to keep windows always clean) or to build completely new products (like complex high speed chips in which transistors are only nanometers in size). Nanotechnologies are present in multiple markets (from leisure, to electronics, food and pharmaceuticals) mostly to add new functionalities to existing products, but they also open up radically new avenues to address numerous prevailing issues (from boosting energy conversion for solar panels, to drug delivery and new structural materials) (Larédo et al., 2010). This is the first time countries outside the Triadic group have made such massive $R \& D$ investments. It has led to the creation of multiple S\&T niches in which national programs have developed and tested new technological demonstrators/prototypes. This hype has also driven private sector activity, with most of the largest world firms now owning nanotechnology patents from chemicals and materials, to health care and pharmaceutical industry, and to electronics and telecommunications, to cite just a few application fields (Larédo et al. 2010). Nanotechnologies are indeed considered as "general purpose technology" (Bresnahan and Trajtenberg, 1995), which promise to impact all fields in a pervasive manner. Lastly civil society at large participates in this movement: NGOs have drawn attention to uncertainties about the environmental and health effects of nanomaterials - and indeed, we know little about their long term effects on human beings or the environment, as matter at the nanoscale does not always have the same physical, chemical, electronic or structural properties as it does at the microscale (Royal Society, 2004; Aitken et al., 2009).

\section{Arena 1: ISO nanotechnologies technical committee on nanotechnologies TC229}

Objective: market structuring by defining terms (WG1), by the selection of recognized HSE process (WG3), and by the definition of technical specifications for B-to-B (WG4)

Actors: companies, public laboratories, specialized agencies and governmental bodies (both technical ministries (labour, health...) and strategic (industry and commerce).

Instruments: technical standards

Legitimacy: technical expertise and rules of consensus for each technical standard developed 
The International Organization for Standardization (ISO) creates standards in all fields. "ISO is the world largest standards developing organization. Between 1947 and the present day, ISO has published more than 18,500 International Standards, ranging from standards for activities such as agriculture and construction, through mechanical engineering, to medical devices, to the newest information technology developments" (ISO website, 2011). The Technical Committee 229 "nanotechnologies" (TC229) was created in 2005 with the objective "to develop science-based standards for the field of nanotechnology in order to promote its commercial applications in a secure manner" (General assembly, June 12th 2009) ${ }^{2}$. As nanotechnologies are transversal, it was initially decided that the TC would develop high-level standards that can be used in all applications while application based standards would be developed in industry specific committees.

ISO TC229 has been successful in attracting many types of experts (Table 1): from high-level scientists with management positions in industry or scientific agencies who felt that something needed to be done to support the development of nanotechnologies, while others, in contrast, are specialists in standards but had, at the start of the Committee, no knowledge of nanotechnologies. 40 delegates attended the first meeting of the committee in 2005, while the attendance in the latest meetings is between 120 and 200 delegates. 30 to 40 delegates constitute the core of the group while the rest of the delegates join in the meeting depending essentially on the location of the meeting: bi annual meetings are organized alternatively in America, in Europe and in Asia, also showing the attractiveness of the TC at a global level. The membership is worldwide: 28 participating countries $(\mathrm{P})$ and 6 observing countries (O) in 2006 and $34 \mathrm{P}$ and $11 \mathrm{O}$ in 2012. In addition to the national delegates, TC229, like any other ISO technical committee, includes representatives from various bodies, called liaisons. The establishment of liaisons in the standardisation system is a way of formalising a contact between activities that are believed to have mutual benefits. This is both seen as a way for efficient communication, which in turn prevents double work and as a way to promote sensible demarcations between areas. The increase from 6 internal liaisons in 2005 to 30 in 2013 and from 0 external liaison to 9 in 2013 also shows the attractiveness of the committee, and the strong position as a coordination entity that the TC has been building over the years. For instance, ISO TC229 received the mandate from CEN (European Standardization Committee) and from OECD to develop terminology standards, while it has co-developed terminology and characterisation standards with the IEC (International Electrotechnical Commission - International standards and conformity assessment body for all fields of electrotechnology).

\footnotetext{
${ }^{2}$ The group produced this first definition of its activities in 2005: "Title: Nanotechnologies; Scope: "Standardization in the field of nanotechnologies that includes either or both of the following: (i) Understanding and control of matter and processes at the nanoscale, typically, but not exclusively, below 100 nanometers in one or more dimensions where the onset of size- dependent phenomena usually enables novel applications; (ii) Utilizing the properties of nanoscale materials that differ from the properties of individual atoms, molecules, and bulk matter, to create improved materials, devices, and systems that exploit these new properties". Source: ISO TC229 archives - N41
} 
Table 1 - membership of TC229

\begin{tabular}{|l|l|l|l|l|}
\hline Date & Meeting location & $\begin{array}{l}\text { Number of } \\
\text { permanent } \\
\text { countries members }\end{array}$ & $\begin{array}{l}\text { Number of } \\
\text { internal liaisons }\end{array}$ & $\begin{array}{l}\text { Number of } \\
\text { external } \\
\text { liaisons }\end{array}$ \\
\hline End of 2005 & London, UK & 23 & 6 & 0 \\
\hline Mid 2006 & Tokyo, Japan & 27 & 7 & 2 \\
\hline End of 2006 & $\begin{array}{l}\text { Seoul, Rep of South } \\
\text { Korea }\end{array}$ & 28 & 15 & 4 \\
\hline Mid 2007 & Berlin, Germany & 29 & 18 & 4 \\
\hline End of 2007 & Singapore, Singapore & & & \\
\hline Mid 2008 & Bordeaux, France & 30 & 21 & 4 \\
\hline End of 2008 & Shanghai, China & 32 & 19 & 4 \\
\hline Mid 2009 & Seattle, USA & 32 & 25 & 7 \\
\hline End of 2009 & Tel Aviv, Israel & 32 & 25 & 8 \\
\hline Mid 2010 & $\begin{array}{l}\text { Maastricht, the } \\
\text { Netherlands }\end{array}$ & 33 & 26 & 8 \\
\hline End of 2010 & Kuala Lumpur, Malaysia & 36 & 26 & 9 \\
\hline Mid 2011 & St Petersburg, Russia & 24 & 27 & 9 \\
\hline End of 2011 & $\begin{array}{l}\text { Johannesburg, South } \\
\text { Africa }\end{array}$ & 34 & 27 & 9 \\
\hline Mid 2012 & Stresa, Italy & 34 & 29 & 9 \\
\hline March 2013 & Queretaro, Mexico & 34 & 30 & 10 \\
\hline
\end{tabular}

TC 229 initially focused its activities around 3 themes that structured the TC's organisation. These were discussed and decided between the experts present during the first two meetings ${ }^{3}$.

JWG 1 "terminology and nomenclature" aims at creating "a common language for scientific, technical, commercial and regulatory processes"(TC 229 Business Plan, 2007). Its mission is "to establish a taxonomic terminology framework for describing and defining nanotechnologies in a clear and unambiguous manner; and thence to explore possible models for a nomenclature framework that could be the basis for appropriate regulatory systems" (Clive Willis, presentation to the general assembly, Nov $\left.21^{\text {st }}, 2008\right)$. It is a joint working group with the IEC.

JWG 2 "measurement and characterisation" is also a joint working group with IEC TC113. It aims at developing standards in measurement, which are "internationally accepted for quantitative scientific, commercial and regulatory activities" (TC 229 Business Plan, 2007).

The objective of WG 3 "health, safety and environmental issues" is to ensure "occupational safety, and consumer and environmental protection, promoting good practice in the production, use and disposal of nano-materials, nanotechnology products and nanotechnology-enabled systems and products" (TC 229 Business Plan, 2007).

It increased its activities in 2008 with a fourth WG "Material specifications", which aims at establishing nanomaterials specifications for professionals and thus at easing B-to-B exchanges on the market. There were pressures to include this fourth working

\footnotetext{
${ }^{3}$ Each national delegation presented its vision of the structure of the TC and the works that TC229 should focus on (a deeper analysis can be found in Delemarle, 2013). The three themes at the core of TC229 were easily acknowledged by the delegations. The core of the discussion was on the structure of the committee i.e. an organization in sub-committees or without sub-committees only based on WG.
} 
group because China was the first country to release a national standard on the subject and the Chinese delegation wanted to translate this national advantage to the global market.

Two transversal task groups (TG) were also added as the TC recognized the need to take into consideration societal concerns.

TG "Nanotechnology and sustainability", created in 2008, is expected to look for areas in which standards can be developed to speed up the process for innovations linked to sustainability and that are close to the market. It is actually aiming at setting priorities for new work items: these items being directly linked to sustainability. An exemplary case is water purification ${ }^{4}$.

TG "Consumer and Societal dimensions of nanotechnology" was created in 2008 to take into consideration all non-technical aspects of nanotechnology including ethical issues such as the participation of countries from the Southern hemisphere, of underrepresented groups and of the consumers.

Table 2 - Activities of TC229

\begin{tabular}{|c|c|c|}
\hline Date & $\begin{array}{c}\text { Total number of } \\
\text { standardization } \\
\text { documents published }\end{array}$ & $\begin{array}{c}\text { Number of projects } \\
\text { discussed* }\end{array}$ \\
\hline November 2005 & 0 & 0 \\
\hline June 2006 & 0 & 1 \\
\hline December 2006 & 0 & \\
\hline June 2007 & 0 & 10 \\
\hline December 2007 & 0 & \\
\hline May 2008 & 0 & 29 \\
\hline Nov 2008 & 0 & 33 \\
\hline June 2009 & 2 & 40 \\
\hline Oct 2009 & 2 & 41 \\
\hline May 2010 & 2 & 44 \\
\hline December 2010 & 7 & 39 \\
\hline May 2011 & 11 & 34 \\
\hline November 2011 & 15 & 32 \\
\hline June 2012 & 23 & 24 \\
\hline
\end{tabular}

* Projects are standardisation documents under development. It takes 24 months to develop a draft that is submitted to vote. Documents need to be published within 36 months ${ }^{5}$.

TC229 grew over time both in size as the number of members and liaisons shows and in number of projects as Table 2 illustrates. TC229 became a central actor in the

\footnotetext{
${ }^{4}$ Water purification was especially highlighted in the dinner speech by the convenor of TC229 during the Tokyo meeting in June 2006. This is one of the few publicly available documents of TC229 on ISO website. (Hatto 2006)

${ }^{5}$ www.iso.org/sites/directives.html\#toc marker-21 (last accessed January, $30^{\text {th }}, 2014$ )
} 
governance of nanotechnologies: its leading role in defining the terms related to nanotechnologies (JWG1) and characterising/measuring it (JWG2) is illustrated by the number of standardisation and standardisation like organisations that rely on it for this work (Table 3). TC229 even plays a role of coordinating entity: ${ }^{6}$ general definitions and characterisation methods/measurement are carried out by TC229, while specific work on applications is carried out by existing industrial TCs, even if this involves working outside of the ISO structure. In 2011 for example, TAPPI, the worldwide Technical Association for Pulp, Paper and related Industries, which is in charge of standardization in those fields, contacted ISO TC229 to coordinate the standardization activities in relation to nanocellulose materials, and it was agreed that ISO TC229 WG1 would work on definition related to nanocellulose and that WG2 would work on their characterization and measurement. To give another example: in 2007, ISO TC229 and the IEC (the International Electrotechnical Commission - in charge of standardization activities in electrotechnology) decided to avoid redundancy by creating joint working groups to manage their nanotechnology-related activities ${ }^{7}$.

Table 3 - Details on some of the external liaisons

\begin{tabular}{|l|l|}
\hline Acronym & Full name \\
\hline $\begin{array}{l}\text { EC-JRC } \\
\text { IRMM) }\end{array}$ & $\begin{array}{l}\text { European Commission - Joint Research Centre (Institute for Reference Materials } \\
\text { and Measurements) }\end{array}$ \\
\hline VAMAS & The Versailles Project on Advanced Materials and Standards \\
\hline ANF & Asia Nano Forum \\
\hline BIPM & $\begin{array}{l}\text { Bureau International des Poids et Mesures (International Bureau of Weights and } \\
\text { Measures) }\end{array}$ \\
\hline ECOS & \begin{tabular}{l} 
European Environmental Citizens Organisation for Standardisation \\
\hline IUPAC
\end{tabular} \\
\hline OECD - WPMN & $\begin{array}{l}\text { Organisation for Economic Co-operation and Development, Working Party on } \\
\text { Nanomaterials }\end{array}$ \\
\hline ETUI & \begin{tabular}{l} 
European Trade Union Institute \\
\hline TAPPI
\end{tabular} \\
\hline
\end{tabular}

TC229's development pattern shows the progressive enrolment of new actors and the enlargement of its scope of activities. The growing number of liaisons but also the increasing activity (as an indicator of the increasing number of experts mobilised to work on the standardisation documents) illustrates this. Its extended scope is illustrated by the development of WG4 and by the set up of the two TGs in 2008

\footnotetext{
${ }^{6}$ So TC229 is transversal across many industries - in 2013, its members come from multiple industries and application committees: biotechnologies, forestry, textiles, electronics, materials etc.

${ }^{7}$ ISO TC229 WG1 and WG2 are Joint WGs between ISO and IEC, bringing together experts from both organizations and producing documents that are published jointly by ISO and IEC.
} 
which both introduced new themes in a technical committee.

TC229 shows its attractiveness as it proposed in 2013 the first standardisation projects that are not directly technical in WG1 (with the support of the OCDE) covering "economic indicators for nanotechnologies" and "terminology - nanotechnologies in plain English".

\title{
Arena 2: Working party on manufactured Nanomaterials (WPMN) at the Organisation for Economic Co-operation and Development (OECD)
}

\author{
Objective: "safety evaluation and assessment of manufactured nanomaterials" \\ Actors: OECD, governmental agencies and ministries, companies \\ Instruments: recommendations, reports, good practices \\ Legitimacy: international organisation whose mission is to "promote policies that improve the \\ economic and social well-being of people around the world" (www.oecd.org)
}

OECD set up in 2006 the Working Party on Manufactured Nanomaterials. It "involves OECD member countries, as well as some non-members economies and other stakeholders to pool expertise and to fund the safety testing of specific Manufactured Nanomaterials" (www.oecd.org). The Working Party on the safety of Manufactured Nanomaterials (WPMN) was created "to ensure that the approaches for hazard, exposure and risk assessment for manufactured nanomaterials are of a high quality, science-based and internationally harmonised" 8 . Its terms of reference state ten points among which the first is "to elaborate and implement a program of work (...) to promote international co-operation in the health and environmental safety related aspects of manufactured nanomaterials ... The main topic areas to be included in the program of work will include: Definitions, nomenclature and characterisation (physicochemical properties, uses) where not otherwise available; Environmental fate and effects (hazard identification, hazard, exposure and risk assessment methods); Human exposure and health effects (hazard identification, hazard, exposure and risk assessment methods); Exchange of information on regulatory and risk management frameworks (limited mainly to the chemicals sector) as well as environmental benefits." 9

Table 4 presents the 37 documents that constitute the outputs of WPMN's work. First, its shows that that their work on "definitions, nomenclature and characterisation" was not carried out. It was transferred to the ISO TC229 in 2008. It is thus an acknowledgment from the OECD that ISO was legitimate to fulfil this task. It then shows a change in focus in relation to the objective of developing methods: the 4 "guidance" documents produced describe "how to do things" rather than "what to do". Last, most documents (25) are actually reviews and summary of what other actors have been doing. This is why the WPMN developed a database regrouping governmental activities linked to EHS issues of nanomaterials. There is thus an important move from what was expected -i.e. assessing manufactured nanomaterials. The failure of the activities of the arena can be explained by the fact that the OECD WPMN relied on national and private support for developing the R\&D processes implied for the characterisation of the nanomaterials. The initial idea was to work first

\footnotetext{
${ }^{8}$ www.oecd.org, downloaded July 2013, 2.

${ }^{9}$ Terms of reference for the working party on manufactured nanomaterials, 2006
} 
on 13 selected manufactured nanomaterials as a test, which would then be replicated to other nanomaterials. However, the slowness in the definition of the nanomaterial characteristics and the R\&D cost led the WPMN to recognize that this could not be reproduced.

Table 4 - List of OECD WPMN outputs at July 2, 2013

\begin{tabular}{|l|l|}
\hline Type of document & Number \\
\hline Gathering of the opinions and activities of participating members & 11 \\
\hline OECD work program & 7 \\
\hline Reviews (including 2 workshops) & 14 \\
\hline "Guidance" documents & 4 \\
\hline List of regulated nanomaterials & 1 \\
\hline Total & 37 \\
\hline
\end{tabular}

The pattern of development of the OECD WPMN thus shows a failure in coordinating activities at the global level and in the assessment of manufactured nanomaterials. It evolved to become an arena that disseminates information produced by others.

\section{Arena 3: International Council on Nanotechnology (ICoN)}

Objective: to share knowledge on health, environmental and safety issues

Actors: a few companies and governmental agencies gathered within the International Council on

Nanotechnology

Instruments: knowledge database and journal

Legitimacy: openness of the database

ICoN is a non-governmental organization that defines itself as "an international, multi-stakeholder organization whose mission is to develop and communicate information regarding potential environmental and health risks of nanotechnology, thereby fostering risk reduction while maximizing societal benefit" (ICoN Fact sheet, $2010)^{10}$. Founded in 2004, "ICON is a knowledge-driven organization [that] does not engage in advocacy or commercial activities [...]. It is composed of members from academia, industry, government and non-governmental organizations ${ }^{11}$ from France, Japan, the Netherlands, Switzerland, Taiwan, the United Kingdom and the United States" (ICON Fact sheet, 2010). It was initially supported by a NBER grant and by Rice University, as well as by industrial sponsorship from DuPont, Intel, Lockheed Martin, L'Oreal, Mitsubishi Corporation, Procter \& Gamble and Swiss Re insurance.

ICoN aims at providing transparent and high quality technical information on health and environmental risk issues in nanotechnologies. Initially, it created a database - the ICON Environmental, Health and Safety (EHS) database - to collect as much data as

${ }^{10}$ July 1 st. 2010 is the date of the last update of the document.

${ }^{11}$ ICoN 27 members 2012 (based on ICoN website)

\begin{tabular}{|l|r|}
\hline & 2012 \\
\hline Public admin. /Govt lab & $33 \%$ \\
\hline University & $15 \%$ \\
\hline Company & $37 \%$ \\
\hline Other & $15 \%$ \\
\hline
\end{tabular}

The most recent changes in the executive board occurred in 2009 when 5 new members joined (2 companies, 2 public administrations and 1 other). Since then, there has been no change in the membership: both individual and organizational members have been very stable over the years. 
possible on these issues. The database has been upgraded into a virtual journal, which contained on November 5th, 2013, 8092 summaries (abstracts) and citations of research papers related to the EHS implications of nanoscale materials covering the period $1962-2013^{12}$. Anyone can propose on-line the inclusion of a new summary provided the paper has already been published in a scientific journal. The database/virtual journal can be searched on nine specific criteria: Method of study, Particle type, paper type, risk exposure group, production method, exposure pathway, exposure of hazard target, content emphasis and target audience.

It is difficult to assess its use: apart from the virtual journal/database, the website has not been updated since 2010, and carries no data on its use. Moreover, almost no one involved in standardization knows about it or has used it as a source of information (Delemarle and Larédo, forthcoming).

ICoN's development pattern thus shows a failure to become the reference repertory for EHS issues related to nanotechnologies. It materialises the initial interests from global actors in the field bringing together under a non-profit organization form, public and private partners. However, the membership has not evolved, showing a lack of attractiveness. The number of abstracts in the virtual journal is still increasing but it results from a process that is not transparent and the choice of abstracts and their referencing is unknown. Moreover, Porter et al. (2008) indicated in their database covering EHS publications 54900 publications up to the end of 2007. The coverage of ICoN database seems thus very limited.

\section{Arena 4: the European Code of Conduct for responsible nanosciences and nanotechnologies research}

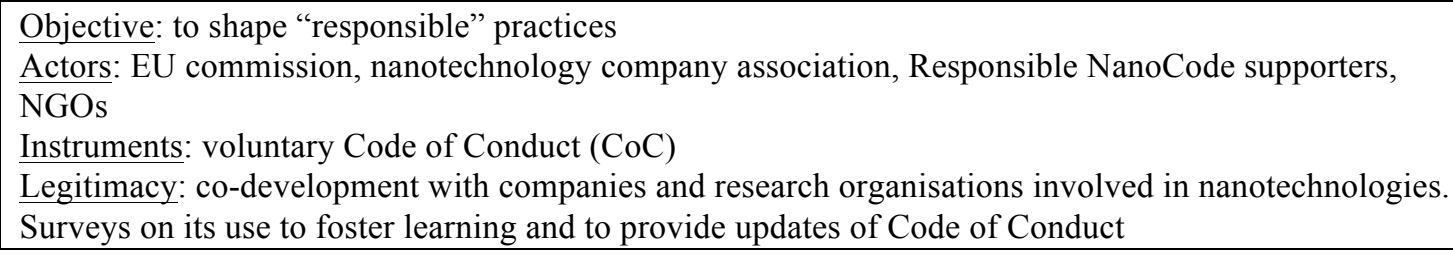

The focus of the EU Commission was to provide guidance for undertaking research not for commercialising products. The European code of conduct $(\mathrm{CoC})$ initially resulted from another initiative: the nanoresponsible code, which was the output of a joint initiative by the UK Royal Society, Insight investment, the Nanotechnology Industrial Association and the UK Nanotechnology Knowledge Transfer Network, who collectively argued on the risk on inaction of business as technical, social and commercial uncertainties were rising (Sutcliffe and Hodgson, 2006) ${ }^{13}$. It was used as

\footnotetext{
${ }^{12}$ On March 8th, 2013, the database contained 7014 summaries, showing that the database is updated.

${ }^{13}$ They brought together members from 8 companies, 4 scientific organisations/universities and 3 NGOs to produce seven principles illustrated by examples and a benchmark after numerous public consultations. The targets of the Code of Conduct are companies' boards because they are said to be the ones able to impose change in companies. "The Code will be designed to establish a consensus of what constitutes good practice in businesses across the nanotechnology value chain (i.e. from research and development to manufacturing, distribution and retailing) so that businesses can align their processes with emerging good practice and form the foundation for the development of indicators of
} 
a basis by the European Commission to produce the EU Code of responsible research in nanotechnology with the support of large European companies.

The European CoC Code of Conduct "encompasses seven general principles on which Member States are invited to take concrete action to ensure that nanotechnologies are developed in a safe manner" ${ }^{\prime 4}$.These are: (i) Meaning; (ii) Sustainability; (iii) Precaution; (iv) Inclusiveness; (v) Excellence; (vi) Innovation; (vii) Accountability. It was proposed as a voluntary approach without certification or accreditation requirement. It was expected that companies would embrace the $\mathrm{CoC}$ both because companies were involved in the creation process, and because it was not regulatory related.

It has been publicized in specific conferences organised by the EU Commission. We investigated the actual use and diffusion of the EU CoC, which is the only way to follow the success or failure of the arena. We selected a sample of 37 companies located in Europe which were identified using the work done on nanotechnology dynamics (Delemarle et al., 2009) ${ }^{15}$. We visited their websites to characterize their 'nanoresponsible' practices: $60 \%$ do mention such practices, but, of these, 9 out of 10 develop their own approach (their own code of conduct or specific guidelines), and none did explicitely refer to the EU CoC (Table 5).

Table 5 - Use and diffusion of the EU CoC in a sample of firms in nanotechnologies

\begin{tabular}{|c|c|c|c|c|c|}
\hline $\begin{array}{l}\text { Number of } \\
\text { companies } \\
\text { who: }\end{array}$ & $\begin{array}{l}\text { do not mention } \\
\text { any specific } \\
\text { guidelines } \\
\text { linked to } \\
\text { nanotechnology }\end{array}$ & $\begin{array}{l}\text { mention specific } \\
\text { guidelines } \\
\text { linked to } \\
\text { nanotechnology }\end{array}$ & $\begin{array}{l}\text { refer to } \\
\text { the EU } \\
\text { CoC }\end{array}$ & $\begin{array}{l}\text { develop their } \\
\text { own CoC or } \\
\text { have a written } \\
\text { position }\end{array}$ & $\begin{array}{l}\text { refer to } \\
\text { industry } \\
\text { practices in } \\
\text { relation to } \\
\text { nano }\end{array}$ \\
\hline 37 & 22 & 15 & 0 & 14 & 3 \\
\hline
\end{tabular}
Some companies developed their own $\mathrm{CoC}$ and also refer to industry specific practices

The EU CoC development pattern thus also shows a failure to become a reference in shaping practices at the European level. The OECD did not develop this aspect either. It was partially developed within the ISO TC229 via the development of a framework on risk management. But, more than a failure of one arena, what we see is the failure of an issue to attract interest and support: less than half of the companies mention specific guidelines linked to their use of nanotechnologies.

\section{Arena 5: nanoREACH (Registration, Evaluation, Authorization and Restriction of Chemical Substances at the nanoscale)}

Objective: to register nanomaterials as chemical substances

Actors: EU Commission, European Chemicals Agency (ECHA), chemical companies and their association

Instruments: regulatory framework enforced by the EU Commission

Legitimacy: legal enforcement by the EU Commission

compliance" (The Responsible NanoCode, 2008). www.responsiblenanocode.org/documents/ theresponsiblenanocodeupdateannouncement.pdf, last accessed, April 15th, 2013).

$14 \mathrm{http} / /$ europa.eu/rapid/pressReleasesAction.do?reference=IP/08/193\&format=HTML, last accessed April 18th, 2012

${ }^{15}$ We selected the top five companies in the main European clusters. This led us to a sample of 37 companies that have activities in Europe but can be companies from other continents. 
The REACH framework is a regulatory framework enforced by the EU commission in 2007: it aims at "ensur(ing) a high level of protection of human health and the environment from the risks that can be posed by chemicals, the promotion of alternative test methods, the free circulation of substances on the internal market and enhancing competitiveness and innovation"16. It is thus a mode of regulation for the chemical industry. The principle that underlies the framework is that manufacturers and importers of chemicals are responsible for the substances they manufacture or import. They must identify and manage risks linked to them ${ }^{17}$. It is thus the actors themselves who are responsible to say what they are using and how they are handling the nanomaterials. For each substance manufactured or imported in quantities of one ton or more per year per company, manufacturers and importers have to fill in a registration dossier, and submit it to the European Chemicals Agency (ECHA) (registration step). Selected substances of high concern may be asked to provide more information (the evaluation step) and some substances, considered of very high concern, are subject to authorisation (the authorisation step). Last the EU authorities can put "restrictions on the manufacture, use or placing on the market of substances causing an unacceptable risk to human health or the environment"18.

Concerns due to uncertainties related to nanomaterials toxicity led actors to question the relevance of REACH framework to handle nanomaterials. While the European Commission stated in 2008 that the "current legislation covers in principle the potential health, safety and environmental risks in relation to nanomaterials", and that "the protection of health, safety and the environment needs mostly to be enhanced by improving implementation of current legislation" (ibidem), several voices raised against REACH as being able to capture the specificities of nanomaterials.

In a nutshell, the controversy lies on the definition of nanomaterials ${ }^{19}$. REACH (and the EU Commission) do not use the definitions set out by ISO for identifying a nanomaterial.

In 2011, the EU Commission adopted the following definition:

\footnotetext{
${ }^{16} \mathrm{http}$ ://ec.europa.eu/enterprise/sectors/chemicals/reach/index en.htm last accessed July, 1st, 2013

${ }_{17} \mathrm{http} / / /$ ec.europa.eu/enterprise/sectors/chemicals/reach/how-it-works/index en.htm last accessed July, 1 st, 2013

${ }^{18}$ COM (2008) 366 final: Communication from the Commission to the European Parliament, the Council and the European Economic and Social Committee: Regulatory aspects of nanomaterials, 17.06.2008

${ }^{19} 3$ projects are developed by the chemical industry and the European chemical association to determine whether a specific nanoREACH needs to be developed in addition to REACH:

- $\quad$ RIP-oN 1 (Substance Identification): the existing REACH registration dossier is considered relevant by industry experts

- $\quad$ RIP-oN 2 (Information Requirements): the existing REACH registration dossier is relevant with a few adjustments. The report concludes: "A comprehensive synthesis of findings, implications, issues and advice has been developed and integrated through the Task Reports and the Final Project Report. Where considered relevant, feasible and justified, specific advice for updating guidance has been provided". http://ec.europa.eu/environment/chemicals/nanotech/pdf/report_ripon2.pdf

- $\quad$ RIP-oN 3 (Exposure \& CSA): the existing REACH registration dossier is relevant with a few adjustments.

The main limit identified was expressed as follows: "for issues which are not currently technically/scientifically mature for developing detailed guidance, the need for further research and development has been indicated" (2011, xii) and experts expect results from OECD work and ISO standardisation work within TC 229 to provide answers in the future.
} 
"Nanomaterial: A natural, incidental or manufactured material containing particles, in an unbound state or as an aggregate or as an agglomerate and where, for $50 \%$ or more of the particles in the number size distribution, one or more external dimensions is in the size range $1 \mathbf{n m}-100 \mathbf{n m}^{20}$.

In specific cases and where warranted by concerns for the environment, health, safety or competitiveness the number size distribution threshold of $50 \%$ may be replaced by a threshold between 1 and $50 \%$.

By derogation from the above, fullerenes, graphene flakes and single wall carbon nanotubes with one or more external dimensions below $1 \mathrm{~nm}$ should be considered as nanomaterials"

The ISO definition is:

"Nanomaterial: material with any external dimension in the nanoscale or having internal structure or surface structure in the nanoscale" 21

"Nanoscale: size range from approximately $1 \mathrm{~nm}$ to $100 \mathrm{~nm}$ "22

The ISO definition if thus more flexible concerning the size range. Experts working on nanoREACH (among which CEFIC members ${ }^{23}$ ) are arguing that the scale effect may appear not only between 1 and $100 \mathrm{~nm}$ and that a product having $45 \%$ of matter at $95 \mathrm{~nm}$ and $55 \%$ at $105 \mathrm{~nm}$ is not considered as a nanomaterial (while a product having $50 \%$ of matter between 1 and $100 \mathrm{~nm}$ is defined as a nanomaterial). Said otherwise, size cannot be a unique identifier for nanoscale effect ${ }^{24}$.

NanoREACH development pattern shows a mixed result. While the chemical industry had been very reluctant for the adoption of REACH, in the case of nanomaterials, industry representatives have involved themselves from the start producing position papers and reference documents that are central to on-going developments. We find an overall position that favours "local" adaptations (for specific couples of products and use) rather than a transversal approach (e.g. a nanoREACH) regulation). Note however that the discussions are still on-going.

\section{Discussion}

\section{Trans arena dynamics}

We have analysed the dynamics of five arenas connected with the shaping of nanotechnology markets, using a very classical approach to STS for evaluating their success: their capacity to enrol new actors and the takeover by other arenas of 'outputs' circulated.

The more an arena enlarges both in scope and in size, the more successful the arena is because it testifies of its relevance for a growing number of actors and because it is trusted to address complementary issues that the initial one considered. This is the case for the ISO that enrols, aggregates and renews the issues it is proposing. It is enrolling new actors when for example it receives the mandate from the OECD and

\footnotetext{
${ }^{20}$ Emphasis added by the authors

${ }^{21}$ ISO/TS 80004-1:2010, 2.4

${ }^{22}$ ISO/TS 12805:2011, 3.2

${ }^{23}$ CEFIC is the European Chemical Industry Council. Its membership entails around 29.000 companies.

${ }^{24}$ Results of RiP-oN 1 found on http://www.cefic.org/Documents/IndustrySupport/REACHImplementation/Workshops/REACH-and-Nano-Workshop/2011-0623/Nano\%20REACH $\% 20$ Workshop $\% 20-\% 20$ RIP-oN1\%20industry $\% 20$ perspective $\% 20$ $\% 20$ Morris\%20Cole.pdf last accessed July $12^{\text {th }}, 2013$
} 
the EU Commission (via the Vienna Agreement between ISO and CEN) to establish a common vocabulary. It is aggregating when for example it encompasses also the issue of risk management ${ }^{25}$, which was partly the objective of the EU Code of Conduct or when it develops external liaisons with other standardisation bodies. It renews its questioning when it includes subjects that were not initially in its scope, as is illustrated by the creation of the two task groups on sustainability and social issues of nanotechnology, or when it develops standardisation documents on economic indicators on nanotechnology.

The second classical criterion of success lies in the ability of an arena to impose its viewpoints to others. When looking at our cases, this goes first with the ability of the arena to embed its outputs into instruments, may these be tangible or not, like a definition, a method or a standard. The EU code of conduct is a good counter example of this: it is just a discourse with no 'operational' translation and no third party to give credibility to firms that say they apply it. This may well explain why few firms refer to it and no firm ever mentioned applying it. The effective measure of success lies then in the takeover of its outputs by other arenas. This is for instance the case of the definition of nanotechnology by ISO when it is taken over by other standardisation bodies or the OECD; but it also enables to define the limits to such a success, when considering the fact that another central arena, REACH and the European Commission, has developed its own definitions, and defector re-opened the debate about what nanotechnologies are.

We consider these two dimensions as translating the notion of output legitimacy as proposed by Borrás and Edler in the introductory chapter. They are central to trans arena dynamics since they imply both a circulation of actors and artefacts between arenas. We assume that the former by their presence insure inter arena coherence in the ways problems are selected, defined and addressed; and that the latter embed in their use, the solutions promoted by the arena that produced them.

Taking these two criteria as a reference point, we consider, in this first part of the discussion, the conditions that favour or hinder the ability of an arena to succeed. From the analysis of the five cases, we derive a first exploratory list of four key aspects to consider, and possibly four key factors, but this remains to be validated on a wider set of situations. The four aspects are the degree of specificity, the degree of openness, the level of transparency and the structuration of the arena. We shall address them in turn.

(1) The degree of specificity of the arena. We clearly face two types of arenas in our 5 cases: those that focus on one aspect of nanotechnology (ICON and toxicology) or one group of actors (the EU code of conduct and firms, or OECD and governments), and those that address the issue at large, whether within one large industry or sector (REACH and the chemical/materials industries) or globally, as ISO does for all industrial sectors. While one may consider that it might be easier for a 'targeted' arena to be recognised as such and be delegated by others the task for which it specialises, our cases seem to show the reverse, it has been very difficult both for OECD and ICON to enlarge their partnership and even to deliver the targeted objective they initially set out to produce. These were two very different configurations since OECD benefitted of a high level 'input' legitimacy being a world reference for all issues dealing with research and innovation, and having worked on

${ }^{25}$ project 7 in WG3 with Environmental Defense (NGO) and Dupont Chemicals 
chemical safety for decades, while ICON was a de novo creation. The ability for an arena to enlarge its composition and to evolve in the topics to cover seems to be linked to a limited degree of specificity of the arena. This does not mean that it does not focus on certain aspects at its creation, but rather that its embedding leaves the possibility to address other topics open: this limits the costs of investment by participating actors and enables learning to take place.

(2) The degree of openness of the arena. How easily can actors join an arena? What are the cognitive prerequisites to participate in debates? Are the two questions that are considered under this aspect. For instance OECD and ISO require formal membership, as representatives of Governments or as members of national delegations. Opening of the OECD WPMN depends upon existing members through invitation to participate to specific work. In the case of ISO, national delegations are supposed to include actors from diverse environments: firms, public research, government representatives and consumer representatives. Similarly, within ISO, actors are liaising in and out of the committee both to get information from what others are doing but also to give information about what TC229 is doing. They, thus, avoid the arena to develop a product in a vacuum without taking into consideration the other products in development. It is thus important to consider the 'degree' of closeness or openness, through the established rules for participation and the connections established with other arenas.

The other face of openness lies in the degree of technical expertise needed to participate to the arena: to what extent the participation in the arena is conditioned by an expertise. The participation to debates within REACH requires a technical expertise in nanomaterials while the participation to the creation of the European Code of Conduct does not require such an expertise.

(3) The third aspect deals with the level of transparency. Transparency relies on the existence of rules of functioning, on the ways the working process is formalised. An outsider who wishes to consult the Icon virtual journal, knows little about how papers are selected. Similarly the OECD has produced four "guidance documents", which production process remains unknown for the outside user. The situation widely differs for ISO, because work and adoption processes are codified process in a series of steps. For each step there is a formal process of adoption that differs depending upon the step. This provides what could be considered as 'process' legitimacy to the outputs coming from ISO.

(4) We were struck by the fourth aspect: the organisational features of arenas. Three out of five arenas identified have developed within the boundaries of existing organisations, while the fourth one was created de novo. Two features seem to matter here. The first one lies in the fact that activities are eased by the existence of stabilised processes that enable to organise the work and to produce robust compromises that generate the outputs. The second one lies in the mobilisation of existing processes to shape outputs and organise their circulation. This is exemplified by OECD WPMN and ISO TC229. Both rely on internal structures based on dedicated secretaries and standard member bodies. In the case of the code of conduct, both aspects are missing, while the case of ICoN shows that it is not enough to have a legal form with an executive board, working groups and activities. Those that have succeeded, at least partly, also have employees, means of implementation, mechanisms to develop activities etc. This organisational aspect is central but has been missing in existing 
research on arenas. The existence of an organisation to support the arena is thus considered as an important element to consider.

We suggest that these four aspects are a way to further disentangle the notion of 'input' legitimacy proposed by Borrás and Edler. It might be useful to further refine the 'input' notion and separate the dimensions that constitute the arena, from those that characterise its working processes - and as, with innovation studies, distinguish between 'input' and 'process' legitimacy.

Below we provide a first attempt to characterise the five arenas. The following table shows two main results: on one hand, there is no arena that addresses positively all four aspects; on the other hand, there seems to be a connection with multiple negative features and failure. Still there is clearly more work needed about understanding how these four aspects are interconnected and related to the deployment of performative arenas.

\begin{tabular}{|l|c|c|c|c|c|}
\hline Criteria & $\begin{array}{l}\text { ISO } \\
\text { TC229 }\end{array}$ & $\begin{array}{l}\text { OECD } \\
\text { WPMN }\end{array}$ & ICoN & EU CoC & REACH \\
\hline Degree of specificity & - & - & + & + & - \\
\hline Degree of openness & $-/+$ & - & - & - & - \\
\hline Level of transparency & + & $-/+$ & - & - & + \\
\hline $\begin{array}{l}\text { Degree of } \\
\text { structuration }\end{array}$ & + & + & $+/-$ & - & + \\
\hline
\end{tabular}

\section{From a multiplicity of arenas to a governance arrangement}

The move from a multiplicity of arenas to a governance arrangement relies on the alignment of arenas. The cases present two kinds of alignment. The alignment exists when others, outside of a given arena, use the product of this arena. This is the case when ISO TC229 develops definitions that are used by others. The products that circulate "punctualise" the work of the arena without having to consider it again (D. Vinck, 1999, 2010). This type of alignment is based on the circulation of arena products. However, the cases also illustrate another type of alignment between arenas: an alignment based on the mandate given by one arena to another to develop a given product. This is the case when OECD or TAPPI gave mandate to ISO TC229 to develop terminology and characterisation for nanotechnologies. We can trace the degree of alignment or misalignment as for example there is between ISO (and its enrolees) and REACH (or nanoREACH) on the definition of nanomaterials. This misalignment is central because it relates to the vision of the organisation of markets for nanomaterials. On one side, there is the vision that there are different markets for nanoproducts while, on the other side, there is the vision that there is one market. This misalignment does not allow yet the set up of a governance arrangement and this is why it currently leads to the re-opening of a debate on the definition of nanomaterials.

More generally, what then are the conditions of alignment? Said differently, how is consensus created within individual arenas, shared and diffused? This remains an open question. Our present hypothesis, looking at the empirical work conducted (but not presented here) is that actors, belonging to several arenas play a critical role. 
These actors may act as gatekeepers (a member of a group who is at its boundary and controls access of outsiders to the group) or brokers (a member of a group that makes a link between two arenas that otherwise would not have been in contact, thus providing access to information). ISO TC229's success is linked to the existence of in and out liaisons with other ISO TCs and with external organisations. It success is also linked to the fact that many national delegation members are also members of other arenas such as the OECD WPMN or the EU CoC. Most often, within ISO TC229, members are not only technical experts recognized in their field, they are also high level experts in their country and within their companies or public organisations reaching to multiple other (political) arenas. Indeed we should not forget that actors are first of all strategic players. They invest in arenas depending on their interests.

A second hypothesis lies in the respective positioning of arenas: arenas can be complementary (that is addressing different issues and aiming at producing different outputs) or competing between them (around the same output). This notion of complementarity is important because as arenas recognize the relevance of other arenas, they can delegate them the role of developing certain outputs (as we have shown, at least partly, for the definition and characterisation of nanotechnology products). Complementary thus fosters alignment. On the contrary, competition fosters uncertainty. We hypothesize that a governance arrangement cannot be stable as long as competition between arenas remains.

\section{Conclusions}

We started this chapter with the ambition to better understand the process through which radical change is governed. We chose to focus on actors' activities to do so. Using on-going situations in the field of nanotechnologies, we follow five arenas in which actors invest. We propose a two-stage approach: in a first stage, 'concerned' arenas are identified and their internal dynamics are studied; and, in the second stage, the articulations between the arenas and their alignment are scrutinised. Thus understanding the governance of change leads to following the building of governance arrangements.

Actors invest in specific arenas to try and influence the future governance arrangement. We have defined successful arenas as those than manage to enrol new actors, enlarge their initial remit while seeing their 'outputs' taken over by other arenas. This enables to see that arenas have various degrees of success or failure. We have proposed a first attempt to delineate four aspects that matter for the effective success of an arena: the degree of specificity, the degree of openness, the level of transparency and the degree of structuration. These aspects enable to disentangle the notion of input legitimacy proposed by Borrás and Edler in their introductory chapter. While the first three have already been studied, we were struck by the importance of the fourth, the structuration of arenas and the critical role of organisational dimensions, not only legal, but even more for favouring work processes, for shaping 'outputs' and for insuring their circulation. One initial reflection is that in four out of the five cases arenas were existing before the issue of nanotechnologies, and that success was linked to their ability to adapt to the new issue. This point clearly needs to be deepened and more research on the organisation of arenas is needed.

Another interesting phenomenon is that the five arenas considered developed directly at the international level, driving even to a reversal of established approaches in the 
case of ISO. Why is it so? Is it only because expertise was distributed or is it an example of a deeper change in S\&T governance?

\section{References:}

Aitken R. J., Creely K. S., Tran C. L. 2004 Nanoparticles: an occupational hygiene review. Sudbury, UK: HSE Books RR274

Bonneuil, C., Joly PB. and C. Marris, Disentrenching Experiment: The Construction of GM Crop Field Trials As a Social Problem, Science Technology Human Values 2008; 33; 201

Borrás, S. and J.Edler, The Governance of Change in Socio-Technical and Innovation Systems: Some Pillars for Theory-Building

Bresnahan, T. F. and Trajtenberg, M., 1995. "General purpose technologies 'Engines of growth'?," Journal of Econometrics, Elsevier, vol. 65(1), pages 83-108, January.

Callon, M. and A. Rip. 1992. Humains, non-humains : morale d'une coexistence. In La Terre outragée. Les experts sont formels edited by J. Theys and B. Kalaora 140-156. Paris : éditions Autrement.

Clarke, A.E, 1991. "Social Worlds theory as Organizational Theory" in Social Organization and Social Process: Essays in Honor of Anselm Strauss, ed. By D.Maines. Hawthorne, NY: Aldine de Gruyter. 119-158

Delemarle, A. and P. Larédo, " Governing markets for radical products by designing market infrastructure. Market infrastructures - towards a market paradigm?", 4S-EASST Conference 2012, Copenhagen Business School, Denmark. October 2012.

Delemarle, A. and P. Larédo, forthcoming, Tentative governance for new markets by creating market infrastructures, special issue Research Policy on tentative Governance, ed. Kuhlman S et al.

Fligstein N. 2001. "The Architecture of Markets: An Economic Sociology of Capitalist Societies." Princeton University Press, Princeton, NJ.

Fligstein, N. and I. Mara Drita, 1996 "How to make a market: reflections on the European Union's Single Market Program" (with Iona Mara Drita), American Journal of Sociology, 102: 1-33.

Fligstein N, 1996 "Markets as politics: a political-cultural approach to market institutions", American Sociological Review, Vol. 61 (August: 656-673).

Geels, F.W., 2002. Technological transitions as evolutionary recon- figuration processes: a multi-level perspective and a case-study. Research Policy 31 (8/9), 1257-1274.

Geels, F.W., 2005. The dynamics of transitions in socio-technical systems: a multi-level analysis of the transition pathway from horse-drawn carriages to automobiles (1860-1930). Technology Analysis \& Strategic Management 17 (4), 445-476.

Kuhlmann S., 2007, Rationales and evolution of public "knowledge policies" in the context of their evaluation. Presentation at the Seminario Internacional CGEE, Rio de Janeiro, December 3-5 2007 
Kuhlmann S. et al. 1999, Distributed Intelligence in Complex Innovation Systems. Final report of the Advanced Science and Policy Policy Planning Network (ASTPP). Karlsruhe.

Larédo P., Delemarle, A and Kahane, B. 2010 Dynamics of Nano Sciences and Technologies : Policy Implications. STI - Science, Technology Industry Review, 1 (1), pp. 43-62

Lawrence, T and Suddaby, R. 2006 'Institutional work' in Handbook of Organization Studies, 2nd edition, S. Clegg, C. Hardy, and T. Lawrence (eds.) London: Sage: 215-254.

Porter, A.L, Youtie, J. Shapira, P. and Schoeneck, D, 2008, Refining search terms for nanotechnology. Journal of Nanoparticle Research, 10(5), 715-728

Rip, Arie, Thomas J. Misa and Johan Schot eds. (1995) Managing Technology in Society: The Approach of Constructive Technology Assessment. London: Pinter Publisher.

The Royal Society \& The Royal Academy of Engineering, 2004, Nanoscience and nanotechnologies: opportunities and uncertainties, 116p

Vinck Dominique, 1999. Les objets intermédiaires dans les réseaux de cooperation scientifique. Contribution à la prise en compte des objets dans les dynamiques sociales. In: Revue française de sociologie. 40-2. pp. 385-414.

Vinck, Dominique, 2010. The sociology of scientific work, Cheltenham, Edward Elgar, p245 